\title{
A novel angiogenesis inhibitor impairs lovo cell survival via targeting against human VEGFR and its signaling pathway of phosphorylation
}

\author{
YM Zhang ${ }^{1}$, BL Dai ${ }^{1}$, L Zheng ${ }^{1}$, YZ Zhan ${ }^{1}$, J Zhang ${ }^{1}$, WW Smith ${ }^{2}$ XL Wang ${ }^{1}$, YN Chen ${ }^{1}$ and LC He ${ }^{*, 1}$
}

Colorectal cancer represents the fourth commonest malignancy, and constitutes a major cause of significant morbidity and mortality among other diseases. However, the chemical therapy is still under development. Angiogenesis plays an important role in colon cancer development. We developed HMQ18-22 (a novel analog of taspine) with the aim to target angiogenesis. We found that HMQ18-22 significantly reduced angiogenesis of chicken chorioallantoic membrane (CAM) and mouse colon tissue, and inhibited cell migration and tube formation as well. Then, we verified the interaction between HMQ18-22 and VEGFR2 by AlphaScreen P-VEGFR assay, screened the targets on angiogenesis by VEGF Phospho Antibody Array, validated the target by western blot and RNAi in lovo cells. We found HMQ18-22 could decrease phosphorylation of VEGFR2(Tyr $\left.{ }^{1214}\right)$, VEGFR1(Tyr $\left.{ }^{1333}\right)$, Akt $\left(\mathrm{Tyr}^{326}\right)$, protein kinase $\mathrm{C} \alpha(\mathrm{PKC} \alpha)\left(\mathrm{Tyr}^{657}\right)$ and phospholipase-C $\gamma-1(\mathrm{PLC} \gamma-1)\left(\mathrm{Tyr}^{771}\right)$. Most importantly, HMQ18-22 inhibited proliferation of lovo cell and tumor growth in a human colon tumor xenografted model of athymic mice. Compared with normal lovo cells proliferation, the inhibition on proliferation of knockdown cells (VEGFR2, VEGFR1, Akt, PKC $\alpha$ and PLC $\gamma-1$ ) by HMQ1822 decreased. These results suggested that HMQ18-22 is a novel angiogenesis inhibitor and can be a useful therapeutic candidate for colon cancer intervention.

Cell Death and Disease (2012) 3, e406; doi:10.1038/cddis.2012.145; published online 11 October 2012

Subject Category: Cancer

Angiogenesis is the process of new capillary formation from pre-existing blood vessels and plays an important role in the growth and spread of cancer. ${ }^{1-3}$ Previous studies suggest that angiogenesis mediates tumor growth and metastases, and that inhibition of new blood vessel formation by antiangiogenesis agents is an approach to fight cancer. ${ }^{3}$ As a target for cancer chemotherapy, blocking angiogenesis could be a strategy to arrest tumor growth. ${ }^{4} \mathrm{~A}$ number of antiangiogenic agents have been reported to inhibit tumor angiogenesis such as sorafenib and sunitinib. ${ }^{5}$ Sorafenib inhibits angiogenesis via inhibition of VEGFR2, VEGFR3 and/or platelet-derived growth factor receptor- $\beta$ (PDGFR- $\beta$ ) ${ }^{6,7}$ sunitinib is a tyrosine kinase (TK) inhibitor that targets VEGFR1 and VEGFR2, PDGFR- $\alpha$ and $\beta, \mathrm{c}-\mathrm{KIT}$, and the FLT-3 and RET kinases. ${ }^{5,8}$ Vascular endothelial growth factor (VEGF) is one of the most important regulators of angiogenesis and a key drug target in anticancer treatment. VEGF binding to its receptor (VEGFR) leads to cell proliferation and new vascular formation by TK pathway. The VEGF/VEGFR pathway becomes an attractive target for anticancer drug design. ${ }^{9}$ Ligands binding VEGFRs in the cell membrane induces receptor dimerization and activation of the latter, and autophosphorylation of specific tyrosine residues within the dimeric complex. ${ }^{10,11}$ VEGF primarily binds to three transmembrane receptors with intracellular TK activity: VEGFR1 (FIt-1), VEGFR2 (Flk-1) and VEGFR3 (FIt-4). ${ }^{12}$ Although both VEGFR1 and VEGFR2 are expressed in the vascular endothelium, the angiogenic activities of VEGFs are transduced mainly through VEGFR2. VEGFR2 is the predominant receptor in angiogenic signaling. Its activation regulates endothelial cell migration, proliferation, differentiation, survival as well as vessel permeability and dilation. Activation of VEGFR1 mediates the growth and survival effects of VEGF, so VEGFR1 may function as a negative regulator of angiogenesis by binding VEGF and preventing its binding to VEGFR2. VEGFR3 is predominantly expressed on lymphatic endothelial cells. ${ }^{13}$ Recent research on the VEGF/VEGFR pathway has led to the development of novel antiangiogenic agents. Clinical trials have shown inhibitors to this pathway are effective in reducing tumor size, metastasis and blood vessel formation. ${ }^{14}$ There are various molecular players and signaling cascades involved in the VEGF/VEGFR pathway, such as the phosphatidylinositol 3kinase (PI3K)/AKT, Ras/Raf/mitogen-activated protein kinase (MAPK) and phospholipase-C $\gamma /$ protein kinase C (PLC $\gamma / \mathrm{PKC})$ pathway. These signaling pathways regulate important cellular functions including cellular proliferation, migration, angiogenesis and apoptosis. ${ }^{15-18}$

HMQ18-22 (Figure 1) was a novel derivative of taspine. Taspine was originally identified from a screen of Radix et Rhizoma leonticis (Hong Mao Qi in Chinese) using cell

\footnotetext{
${ }^{1}$ Institute of Materia Medica, School of Medicine, Xi'an Jiaotong University, Xi'an, China and ${ }^{2}$ Department of Pharmaceutical Sciences, School of Pharmacy, University of Maryland, Baltimore, MD, USA

${ }^{*}$ Corresponding author: LC He, School of Medicine, Xi'an Jiaotong University, No. 76, Yanta Weststreet, \#54, Xi'an, Shaanxi Province 710061, People's Republic of China. Tel: + 8629 82656264; Fax: + 86298265 5451; E-mail: helc@mail.xjtu.edu.cn

Keywords: HMQ18-22; angiogenesis; VEGFR; inhibition; signaling pathway

Abbreviations: VEGF, vascular endothelial growth factor; VEGFR, VEGF receptor; FBS, fetal bovine serum; ELISA, enzyme-linked immunosorbent assay; WB, western blot analysis; PCR, polymerase chain reaction; CAM, chicken chorioallantoic membrane

Received 15.5.12; revised 14.8.12; accepted 21.8.12; Edited by A Stephanou
} 


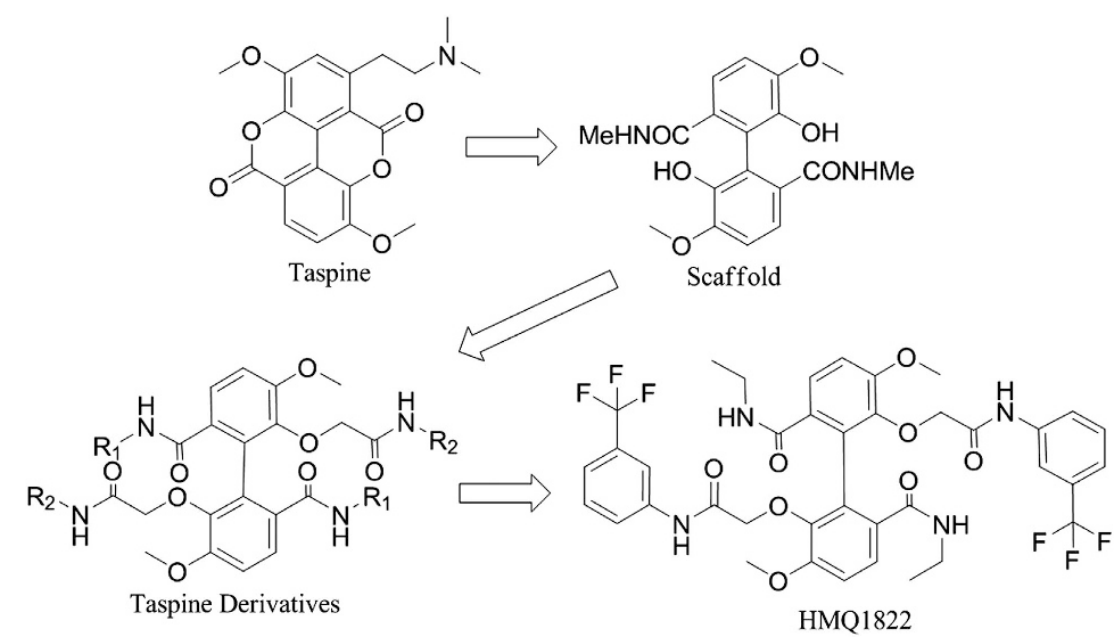

Figure 1 Diagram of the HMQ18-22 synthesis

membrane chromatography. ${ }^{19}$ We previously found that taspine could enter cells and had good affinity to overexpressed VEGFR cell membrane chromatography model and displayed anticancer and antiangiogenesis properties and therefore we used it as a leading compound for anticancer agents development with the aim to increase activity and solubility. A series of ring-opened and biphenyl derivatives have been designed and synthesized using dissection strategies. ${ }^{20,21}$ Among the derivatives, we found HMQ18-22 had good activity and inhibition on lovo cell. In the present study, we investigated the effects and mechanisms of HMQ18-22 on angiogenesis using tissue and cell model in vitro and mouse models in vivo.

\section{Results}

HMQ18-22 inhibited the angiogenesis of CAM and mouse colon tissue. To test the effects of HMQ18-22 on chorioallantoic membrane (CAM) blood vessels, we treated them with HMQ18-22 $(0,2.5,5,10 \mu \mathrm{g} /$ per egg) for $72 \mathrm{~h}$, and found HMQ18-22 inhibited the CAM angiogenesis in a dosedependent manner (Figures $2 a$ and b). The mean IC50 for large vessels, small vessels and capillaries was $3.42 \mu \mathrm{g} / \mathrm{egg}$. In the negative group, rich blood vessels grew and the density and area of the CAM blood vessels increased with incubation time increased. HMQ18-22 inhibited the new capillary vessels formation.

To assess whether HMQ18-22 alters microvessels growth, we used rat colon tissues as a model. We dissected rat colon tissues and subcultured the resultant cells. Microvessel outgrowths of colon tissue in matrigel were increased with the culture time increased (Figure 2ci-c5). Many new microvessels grew after 5 days, and the density and area of the blood vessels tended to increase after 7 days in the untreated control group (Figure 2d), whereas microvessels were less in the HMQ18-22-treated group (Figure 2c6-c8). HMQ18-22 at concentrations of 4.0 and $16.0 \mu \mathrm{mol} / / \mathrm{l}$ significantly inhibited microvessel outgrowths of colon tissue $(P<0.05)$ (Figure $2 \mathrm{e})$.

HMQ18-22 inhibited cell migration and tube formation. To test the effect of HMQ18-22 on cell migration and tube formation, HUVEC cells were induced by VEGF and treated with vehicle or HMQ18-22. HUVEC cells were incubated on matrigel for $48 \mathrm{~h}$ with VEGF, forming an extensive and enclosed network of tubes. HMQ18-22 significantly decreased the number of the tube structure (Figure $3 a$ ) at the concentrations of $0.5-8.0 \mu \mathrm{mol} / /$, respectively. Furthermore, HMQ18-22 also inhibited the HUVEC cell migration (Figure $3 b$ ). In addition, tube formation of colon tissue in the fibrin matrices showed HMQ18-22 also inhibited the number of the tube structure compared with untreated control tissues (Figures $3 c$ and $d$ ).

HMQ18-22 decreased phosphorylation of VEGFR2, VEGFR1, Akt, PKC $\alpha$ and PLC $\gamma-1$ involved in angiogenesis. HMQ18-22 decreased cell survival in lovo and HUVEC cells, and showed dose-dependent inhibition on cell growth (Figure 4a). It suggests that HMQ18-22 displays antiproliferative effect on the lovo and HUVEC cells. The lance assay was used to assess the effects of HMQ18-22 on VEGFR2 kinase activity. The optimized used concentrations of reaction system were as follows: VEGFR2 kinase $0.003767 \mathrm{ng} / \mu \mathrm{l}$, ATP $1.332 \mu \mathrm{M}$ and substrate $121.4 \mathrm{nM}$, respectively. The IC50 of HMQ18-22 on VEGFR2 kinase activity was over $5000 \mathrm{~nm}$, suggesting that HMQ18-22 did not alter VEGFR2 kinase activity effectively. The AlphaScreen assay, an effective method for screening a broad range of targets, was used to determine the effect of HMQ18-22 on VEGFR. We found that HMQ18-22 acted on VEGFR by inhibiting its phosphorylation (Figure 4b).

To further assess whether HMQ18-22 alters the downstream signaling events of VEGFR, a phospho-specific antibody microarray (PVE185) targeting the VEGF Phospho signaling pathway was used. This antibody array included 190 VEGF-related proteins (85 pairs), each with six replicates (raw data in Supplementary Table 2). The paired antibodies for the same (but unphosphorylated) target sites were also included in the array to allow determination of the relative level of phosphorylation. Using a cutoff ratio of 0.88 , we identified five pairs of phosphorylation sites of tyrosine, namely VEGFR2 $\left(\operatorname{Tyr}^{1214}\right)$, VEGFR1 $\left(\operatorname{Tyr}^{1333}\right)$, Akt $\left(\mathrm{Tyr}^{326}\right)$, PKC $\alpha\left(\mathrm{Tyr}^{657}\right)$ and PLC $\gamma-1\left(\right.$ Tyr $\left.^{771}\right)$, were decreased by HMQ18-22 in lovo cell. 
a
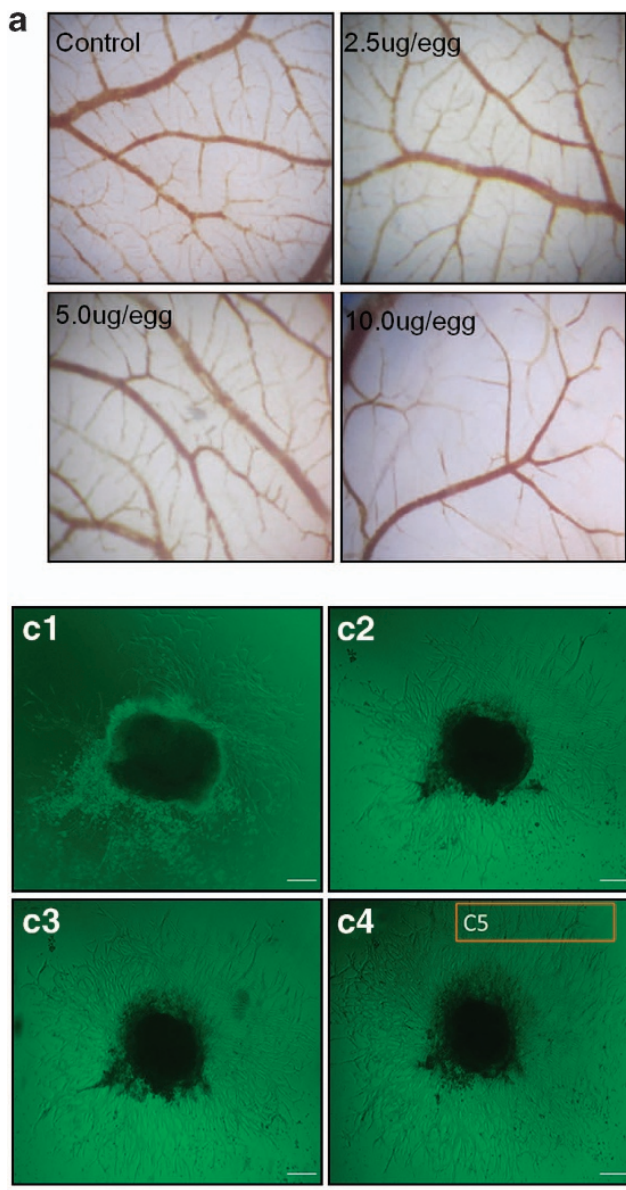

d

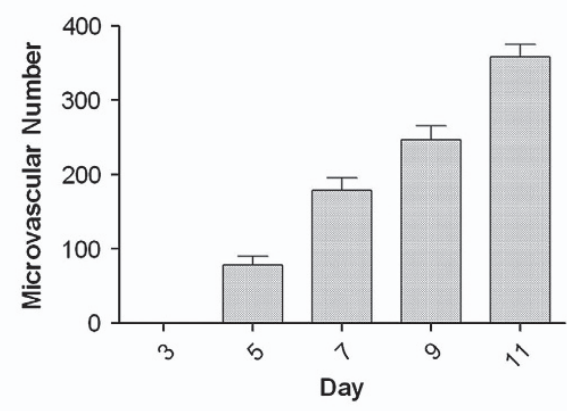

c2 b

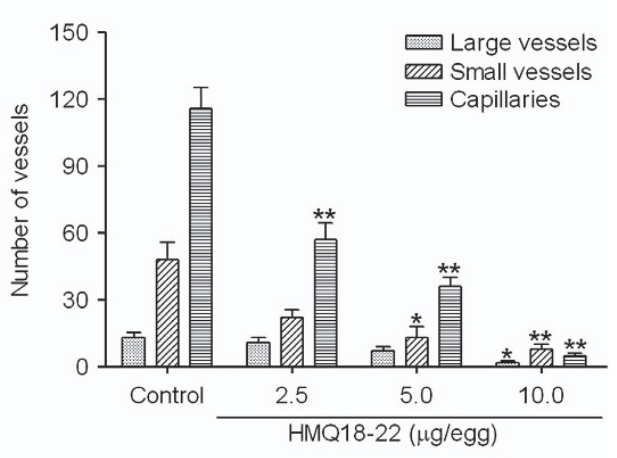

c5

c6

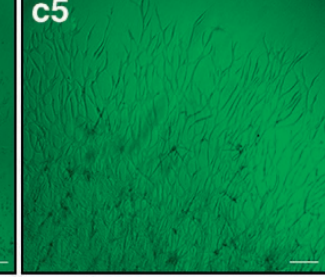

c6

c7

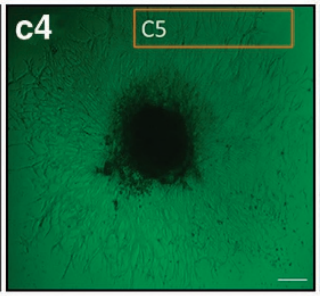

e

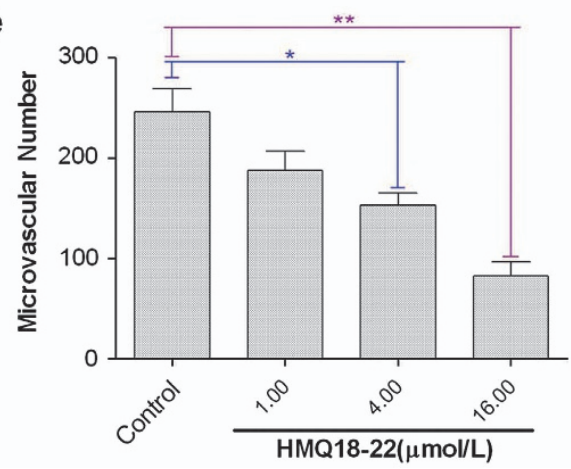

Figure 2 HMQ18-22 inhibits angiogenesis in the CAM and colon tissues. (a) The representative images of CAM blood vessels ( $\times 40$ magnification): in the control group, the blood vessels grew normally; CAM blood vessels in the HMQ18-22 $(2.5,5,10 \mu \mathrm{g} / \mathrm{egg})$-treated group did not increase as quickly as that of the untreated group. (b) Quantification of (a): compared with the negative control group, HMQ18-22 showed the inhibitory effect on the normal CAM angiogenesis in a dose-dependent manner. ${ }^{*} P<0.05$ versus the untreated control group. (c1-c8) HMQ18-22 inhibited microvessel outgrowth of cultured colon tissues $(\times 100$ magnification). (c1-c5) The untreated control group (c1) day 5; (c2) day 7; (c3) day 9; (c4) day 11; (c5) The high magnification of the inset on the 11th day; (c6-c8) in the HMQ18-22-treated group, (c6) 4.0 $\mu$ mol// HMQ18-22 on day 5; (c7) $4.0 \mu \mathrm{mol} / / \mathrm{HMQ18-22}$ on day 11; (c8) The high magnification of the inset treated with $4.0 \mu \mathrm{mol} / / \mathrm{HMQ18}-22$ on day 11. Scale bar, 100 $\mu \mathrm{m}$. (d) Quantification of microvessels in the control group with the increased days. (e) Quantification of microvessels in the HMQ18-22-treated group. Microvascular number indicated the microvessel number grown from the rat colon tissues. Data were expressed as mean values \pm S.D. $(n=5)$. ${ }^{*} P<0.05$, ${ }^{* \star} P<0.01$ versus the untreated control group

To validate the antibody array results, we tested the phosphorylation status of VEGFR2(Tyr $\left.{ }^{1214}\right)$, VEGFR1 $\left(\mathrm{Tyr}^{1333}\right), \operatorname{Akt}\left(\mathrm{Tyr}^{326}\right), \operatorname{PKC} \alpha\left(\mathrm{Tyr}^{657}\right)$ and PLC $\gamma-1\left(\mathrm{Tyr}^{771}\right)$ in lovo cell by western blot analysis. Phosphorylation of Raf1(Tyr $\left.{ }^{341}\right)$ was not affected from the results of antibody array, thus being used as the negative control protein.
HMQ18-22 significantly reduced the phosphorylation of VEGFR2(Tyr $\left.{ }^{1214}\right)$, VEGFR1 $\left(\operatorname{Tyr}^{1333}\right), \quad$ Akt $\left(\operatorname{Tyr}^{326}\right), \quad$ PKC $\alpha$ $\left(\mathrm{Tyr}^{657}\right.$ ) and PLC $\gamma-1\left(\mathrm{Tyr}^{771}\right)$ (Figure 4c). Therefore, the results of microarray with western blotting verified that VEGFR2 $\left(\mathrm{Tyr}^{1214}\right)$, VEGFR1 $\left(\mathrm{Tyr}^{1333}\right)$, Akt $\left(\mathrm{Tyr}^{326}\right), \operatorname{PKC} \alpha\left(\mathrm{Tyr}^{657}\right)$ and PLC $\gamma-1\left(\right.$ Tyr $\left.^{771}\right)$ were the targets of HMQ18-22. 
a
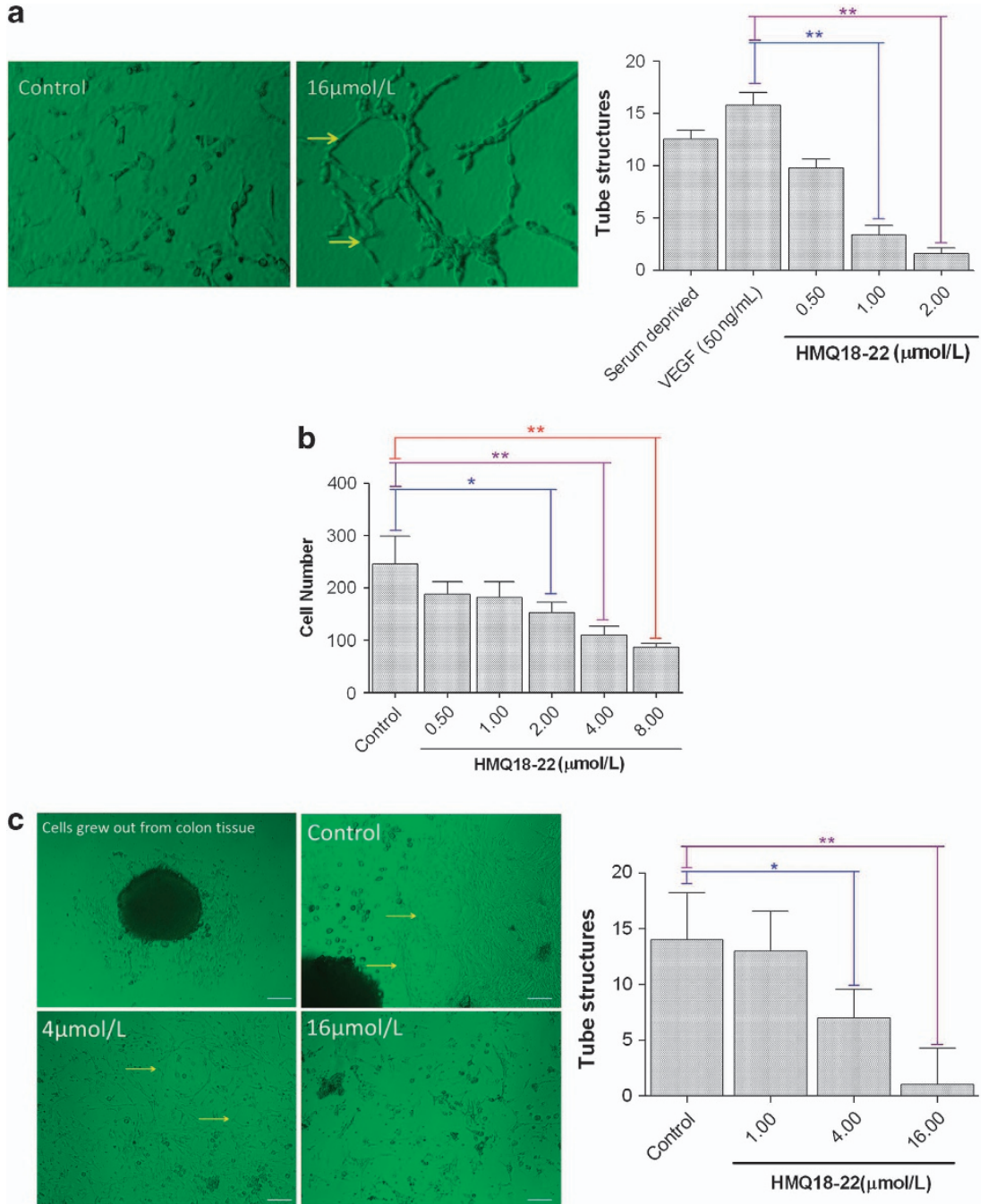

Figure 3 HMQ18-22 inhibited the migration and tube formation of cultured lung tissues and HUVEC cells. (a) Tube formation and quantitation data of tube formation of HUVEC cells treated with vehicle or HMQ for $48 \mathrm{~h}$. (b) Dose-response study of HMQ18-22 on the migration of HUVEC. (c) Effect of HMQ18-22 on the tube formation of colon tissues (magnification $\times 100$ ) and its quantitation data. Scale bar, $100 \mu \mathrm{m}$. Data were expressed as mean values \pm S.D. $(n=5)$. ${ }^{*} P<0.05,{ }^{* *} P<0.01$ versus the untreated control group.

To further assess the roles of VEGFR2, VEGFR1, Akt, PKC $\alpha$ and PLC $\gamma-1$ phosphorylation in cancer cell growth, siRNA targeting these proteins were transfected into cells and followed by HMQ18-22 treatment for 48 h. IC50 of HMQ1822 in survival of lovo cells transfected with siRNA targeting VEGFR2, VEGFR1, Akt, PKC $\alpha$ and PLC $\gamma$-1 was 59.66, 41.67, $88.79,49.98$ and $24.48 \mu \mathrm{M}$ (Figure $4 \mathrm{~d}$ ), respectively, while IC50 in untransfected control cells was only $14.01 \mu \mathrm{M}$ (Figure 4a).

HMQ18-22 inhibited tumor growth of xenografted model in athymic mice. To further assess the effects of HMQ1822 on tumor growth in vivo, human tumor models xenografted in athymic mice were used (Figure 5a). HMQ18-22 significantly inhibited tumor growth in lovo xenografted athymic mice. Compared with the untreated group, HMQ18-22 significantly inhibited tumor growth at a rate of 21.25 and $44.84 \%$, respectively. Furthermore, there was no change in athymic mice body weight during the experiment (the mean body weight at start was $21.14 \pm 1.32 \mathrm{~g}$, $21.50 \pm 0.98 \mathrm{~g}$ and $21.71 \pm 1.16 \mathrm{~g}$ in the control group, $50.0 \mathrm{mg} / \mathrm{kg}$ and $100.0 \mathrm{mg} / \mathrm{kg}$ group, and at end was $25.51 \pm 2.95 \mathrm{~g}, 25.02 \pm 3.26 \mathrm{~g}$ and $25.92 \pm 4.65 \mathrm{~g}$, respectively), which suggested that the dose of HMQ18-22 did not have a toxic effect on athymic mice. We further tested the phosphorylation status of VEGFR2 $\left(\mathrm{Tyr}^{1214}\right)$, VEGFR1 $\left(\operatorname{Tyr}^{1333}\right), \operatorname{Akt}\left(\operatorname{Tyr}^{326}\right), \operatorname{PKC} \alpha\left(\operatorname{Tyr}^{657}\right)$ and PLC $\gamma-1\left(\mathrm{Tyr}^{771}\right)$ in lovo tumor tissue of athymic mice by western blot analysis. We found that HMQ18-22 significantly decreased the phosphorylation of VEGFR2(Tyr $\left.{ }^{1214}\right)$, VEGFR1 $\left(\mathrm{Tyr}^{1333}\right)$, Akt $\left(\mathrm{Tyr}^{326}\right), \operatorname{PKC} \alpha\left(\mathrm{Tyr}^{657}\right)$ and PLC $\gamma-1\left(\mathrm{Tyr}^{771}\right)$ in tumor tissues compared with the untreated group (Figure $5 b$ ). Figure $5 \mathrm{c}$ indicated that the proteins phosphorylation of VEGFR2, VEGFR1, Akt, PKC $\alpha$ and PLC $\gamma-1$ in the HMQ1822-treated group were significantly downregulated in a dosedependent manner compared with the negative control $(P<0.05)$. The results were in line with the corresponding data in lovo cells. 
a

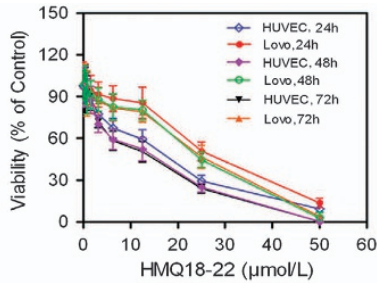

C

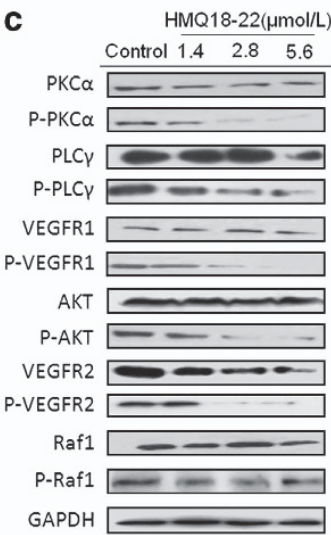

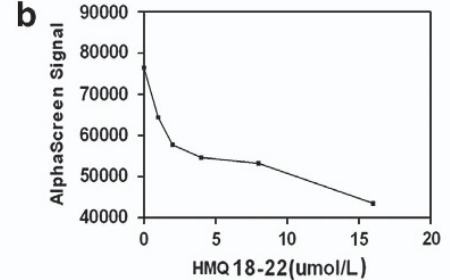

HMQ 18-22(umol/L)

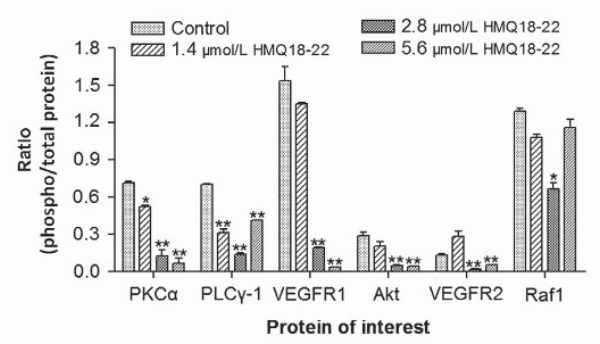

d
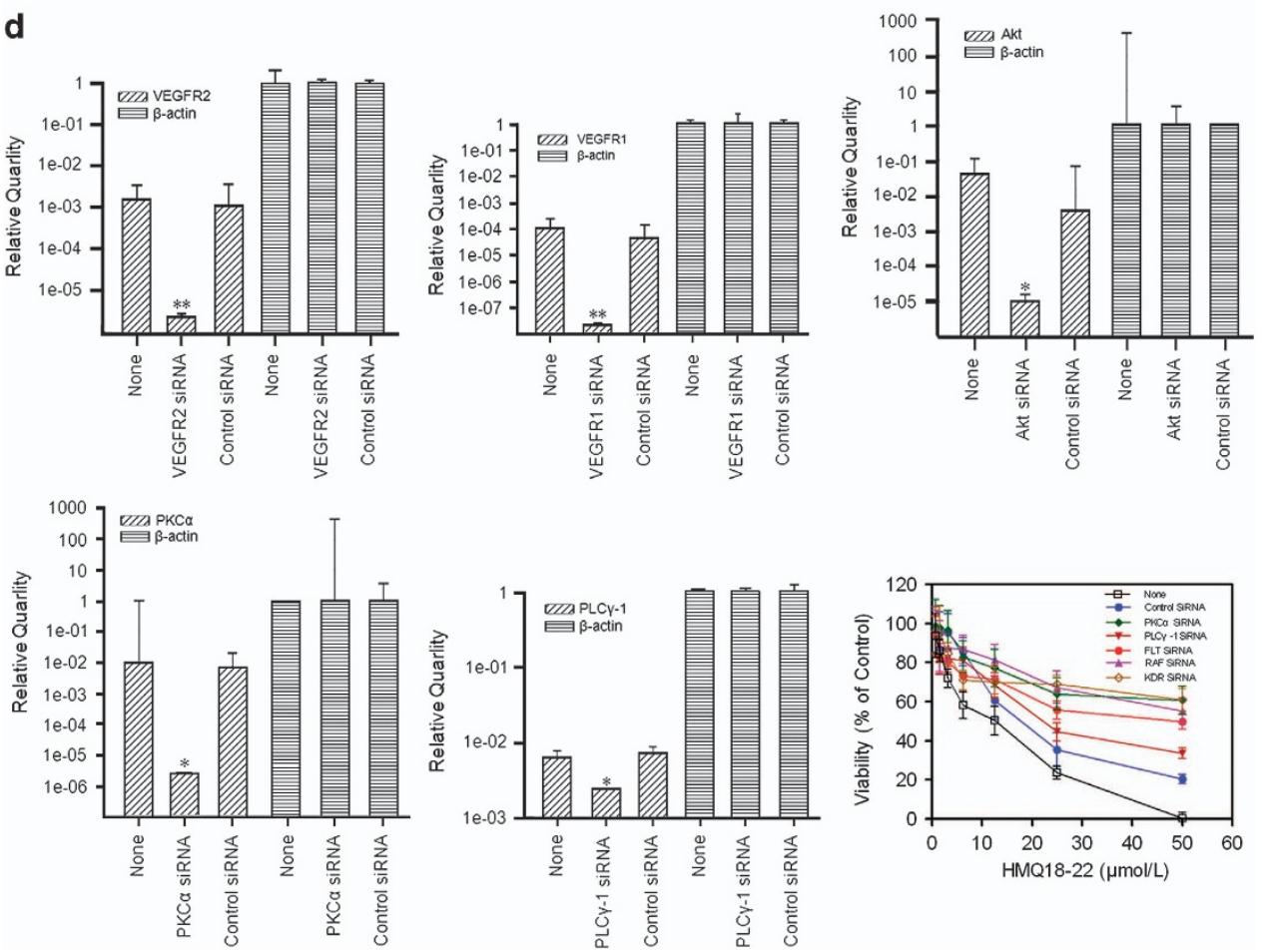

Figure 4 HMQ18-22 inhibited cell viability and decreased phosphorylation of VEGFR2, VEGFR1, Akt, PKC $\alpha$ and PLC $\gamma-1$ involved in angiogenesis. (a) HMQ18-22 decreased cell survival in lovo and HUVEC cells. (b) The AlphaScreen signal indicated HMQ18-22 decreased VEGFR phosphorylation. (c) Cell were treated with VEGF $(50 \mathrm{ng} / \mathrm{ml})$ for $30 \mathrm{~min}$ before extracting proteins with RIPA lysis buffer. HMQ18-22 decreased the phosphorylation of VEGFR2(Tyr $\left.{ }^{1214}\right)$, VEGFR1(Tyr $\left.{ }^{1333}\right)$, Akt(Tyr $\left.{ }^{326}\right)$, PKC $\alpha$ $\left(\mathrm{Ty}^{657}\right)$ and PLC $\gamma-1\left(\mathrm{Tyr}^{771}\right)$ by western blot analysis. On the contrary, the Raf1(Tyr $\left.{ }^{341}\right)$ phosphorylation was not altered by HMQ18-22. Results were quantified by densitometry analysis of the bands form and then normalization to GAPDH protein. (d) Effect of HMQ18-22 on cells transfected with siRNAs targeting of VEGFR2, VEGFR1, Akt, PKC $\alpha$ or PLC $\gamma-1$. Quantification of RT-PCR data showed knockdown of VEGFR2, VEGFR1, Akt, PKC $\alpha$ and PLC $\gamma-1$; the bottom right panel showed the effect of HMQ1822 on cells proliferation was attenuated in knockdown cells. Data were expressed as mean values \pm S.D. $(n=3) .{ }^{*} P<0.05,{ }^{*} P<0.01$ versus the untreated control group.

\section{Discussion}

Colorectal cancer represents the fourth commonest malignancy, and constitutes a major cause of significant morbidity and mortality among other diseases. In this study, the novel compound, HMQ18-22 (a novel taspine analog) significantly reduced angiogenesis of CAM and mouse colon tissue, inhibited cell migration and tube formation and decreased 
a
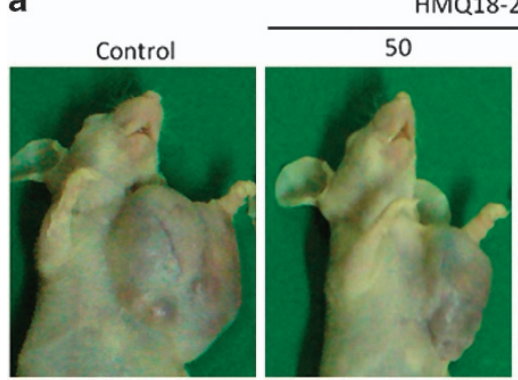

C

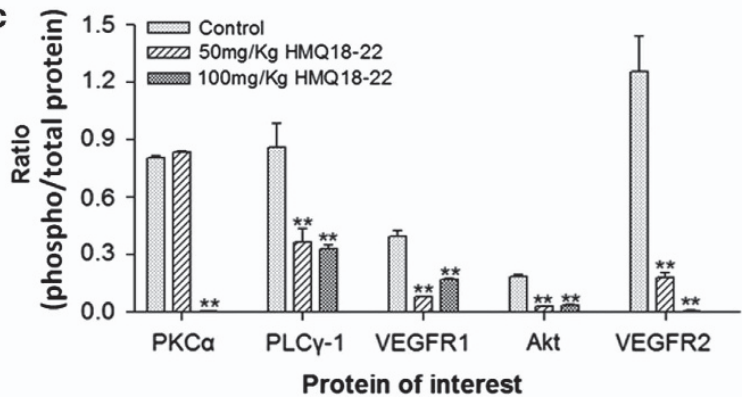

b

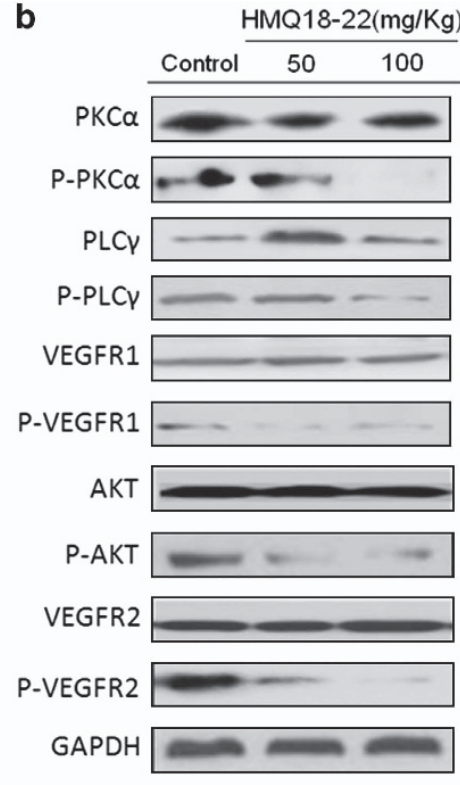

Figure 5 HMQ18-22 inhibited tumor growth in nude mice bearing human colon cancer xenografts. (a) The representative xenografts of lovo human colon cancer in mice. (b) HMQ18-22 decreased the phosphorylation of VEGFR2(Tyr $\left.{ }^{1214}\right)$, VEGFR1 $\left(\right.$ Tyr $\left.^{1333}\right)$, Akt $\left(\right.$ Tyr $\left.^{326}\right)$, PKC $\alpha\left(\right.$ Tyr $\left.^{657}\right)$ and PLC $\gamma-1\left(\right.$ Tyr $\left.^{771}\right)$ in the tumor tissues by western blot analysis. (c) Quantitation data of (b). Data were expressed as mean values \pm S.D. $(n=3)$. ${ }^{\star \star} P<0.01$ versus the untreated control

phosphorylation of VEGFR2, VEGFR1, Akt, PKC $\alpha$ and PLC $\gamma-1$. Most importantly, HMQ18-22 inhibited tumor cell growth in xenografted model in athymic mice. These results suggest that HMQ18-22 can be a useful therapeutic candidate for colon cancer intervention.

HMQ18-22 was synthesized by our group for cancer drug development. Our data showed that HMQ18-22 significantly blocked angiogenesis using CAM model. Angiogenesis plays a vital role in growth, intravasation and metastatic spread of cancer. Inhibition of angiogenesis provides a good chance of preventing cancer from becoming malignant. Tumor angiogenesis shows a markedly increasing proliferation of endothelial cell and has significant functional and structural differences in the vascular plexus. In solid tumors, angiogenesis is well characterized as a critical step for growth, invasion and metastasis. ${ }^{3,22,23}$ To further validate our results of HMQ18-22, we established a new colon angiogenesis tissue model. In this model, the tissues cultured from colon were grown in a three-dimensional matrix (usually fibrinogen or matrigel). In this model, new capillary vessels erupted from the tissue in matrigel, and new erupted endothelial cells grew from tissues in fibrinogen proliferated and formed tube. These results generated by total nutritive index difference between fibrinogen and matrigel. The different type from the two culture mediums in the colon tissue model could be used to assess angiogenesis and tube formation at tissue and organ Level. HMQ18-22 inhibited the sprouting of new vessel from the tissue and tube formation by the erupted endothelial cells, further supporting the notion that HMQ18-22 suppressed the neovascularization.

The VEGF/VEGFR pathway was an important regulator in tumor angiogenesis. It has led to the development of novel antiangiogenic agents. The various downstream signaling molecular players, such as PI3K/AKT, MAPK and PLC $\gamma /$ PKC, have the specific functions including cellular proliferation, migration, angiogenesis and apoptosis. ${ }^{16-18}$ Phospholipase C- $\gamma$ 1(PLC- $\gamma 1$ ), a very important member of phospholipase C (PLC) families, is upregulated in many cancer tissues and cancer cell lines and has been found to participate in many physical processes such as cell proliferation, motility, differentiation, cytoskeleton rearrangement and so forth. ${ }^{24,25}$ There is an intimate relation between PLC- $\gamma 1$ and $\mathrm{PKC} \alpha$. Activated PLC- $\gamma 1$ can catalyze the hydrolysis of phosphatidylinositol 4,5-bisphosphate (PIP2) to inositol 1,4,5-triphosphate (IP3) and diaeylglyeerol (DAG). DAG and IP3 are second messengers to activate PKC. A decrease in the extent of tyrosine phosphorylation of PLC- $\gamma 1$ has also been proved to be positively regulated by $\mathrm{PKC} \alpha{ }^{26,27}$ So, downregulation of surface receptor expression represents a mechanism in which decreased PLC might block PKC activation. Furthermore, in the signaling pathway, PI3K/AKT mediated cell proliferation, migration, invasion, angiogenesis and metastasis. ${ }^{28}$ Akt is a kinase in the signal transduction, making it a potential target. The Akt/PKB kinase has been implicated in the genesis and/or progression of numerous human tumors, because AKT has a wide range of downstream targets that regulate endothelial cell functions such as migration, growth, proliferation and apoptosis. ${ }^{29}$ HMQ18-22 acted on VEGFR and inhibited the phosphorylation of VEGFR by p-VEGFR AlphaScreen assay. However, VEGFR kinase activity was not affected by HMQ18-22, indicating that the inhibition of VEGFR phosphorylation is not due to inhibition on kinase of VEGFR2 Kinase. Using a phospho-antibody array to screen the potential target in the VEGF/VEGFR pathway, we found that 
the phosphorylation of VEGFR2, VEGFR1, Akt, PKC $\alpha$ and PLC $\gamma-1$ were inhibited by HMQ18-22. We further confirmed the array data by western blots using antiphosphorylation antibodies against VEGFR2, VEGFR1, Akt, PKC $\alpha$ and PLC $\gamma-1$ in culture cells and in vivo human colon cancer mouse models. Knockdown of VEGFR2, VEGFR1, Akt, PKC $\alpha$ or PLC $\gamma-1$ by siRNA significantly attenuated tumor inhibitory effects of HMQ18-22. Taken together, these results suggest that $\mathrm{HMQ18-22}$ inhibits tumor angiogenesis and tumor growth by downregulating the phosphorylation signaling of VEGFR2, VEGFR1, Akt, Raf1, PKC $\alpha$ and PLC $\gamma-1$. A compound exerts its action by entering the cell or acting on the cell membrane receptor with good affinity. In previous reports, taspine could enter the cell or act on the cell membrane receptor determined by HPLC-MS and cell membrane chromatography. ${ }^{30}$ HMG18-22 is a derivative of taspine, so HMG18-22 should exert its inhibition and downregulate the phosphorylation signaling by entering the lovo cells and being with good affinity with VEGFR-1 and VEGFR-2.

In conclusion, our results demonstrate that HMQ18-22 might be a novel angiogenesis inhibitor that reduces angiogenic responses in vivo and in vitro by blocking VEGFR signaling pathways. The effectiveness of HMQ18-22 in disrupting colorectal tumor growth provides a promising anticancer agent for further clinical trial for HMQ18-22 to colorectal cancer treatment.

\section{Materials and Methods}

Reagents. HMQ18-22 was from the Research and Engineering Center for Natural Medicine, Xi'an Jiaotong University. Trypsin and fibrinogen were from Sigma (St Louis, MO, USA). Human VEGF was from Peprotech Asia (Rehovot, Israel). WST, protease inhibitor cocktail and phosphatase inhibitor cocktail were from Roche (Roche Tech., Mannheim, Germany). Fibrin matrices were from Sigma and BD Matrigel Basement Membrane Matrix was from BD Biosciences (San Jose, CA, USA). VEGFR2 kinase was from Carna Biosciences (Kobe, Japan). HTRF VEGFR2 kinase kit was purchased from Cisbio (Codolet, France). P-VEGFR2 AlphaScreen SureFire kit was purchased from Perkin-Elmer (Boston, MA, USA). Anti-phospho-VEGFR2 (Tyr $\left.{ }^{1214}\right)$, anti-phospho-VEGFR1 (Tyr ${ }^{1333}$ ), anti-phospho-Akt $\left(\mathrm{Tyr}^{326}\right)$, anti-phospho-PKC $\alpha\left(\mathrm{Tyr}^{657}\right)$, anti-phospho-PLC $\gamma-1$ $\left(\mathrm{Tyr}^{\mathrm{r} 71}\right)$ and anti-phospho-Raf1 (Tyr340/Tyr341) were purchased from Cell Signaling (Cell Signaling Tech., Danvers, MA, USA). Rabbit anti-GAPDH was purchased from Santa Cruz Biotech (Santa Cruz, CA, USA). Rabbit anti-mouse IgG, goat anti-rabbit IgG, BCA protein assay reagent kit and enhanced chemiluminescent $(E C L)$ plus reagent kit were obtained from Pierce (Pierce Biotech, Rockford, IL, USA). Total RNA extracted kit was from Fastagen (Fastagen, China). Revert AID First-strand cDNA synthesis kit was from Fermentas (Hanover, Lithuania). RNAi was from Fermentas. Other reagents used were analytical grades.

Animals and cell culture. In all, 6-8 weeks ALB/C nude male mice were used for all experiments and each procedure was approved by the regional authorities according to China animal-care regulations. Lovo cells from Shanghai Institute of Cell Biology in the Chinese Academy of Sciences were maintained in RPMI1640 with 10\% FBS. HUVEC from ATCC was cultured in F-12K media supplemented with $0.1 \mathrm{mg} / \mathrm{ml}$ heparin, $0.5 \mathrm{mg} / \mathrm{ml}$ endothelial cell growth supplement (ECGS) and 10\% FCS.

CAM assay. CAM was prepared as described. ${ }^{31,32}$ Briefly, a circular window was opened aseptically on the egg shell, and the eggs were replaced into the incubator for $24 \mathrm{~h} 10 \mu \mathrm{l} \mathrm{HMQ18-22}$ was added to the CAM surface in every egg. Doses of 2.5, 5 and $10 \mu \mathrm{g} / \mathrm{egg}$ were used here. At least 10 eggs were used for each sample dose. The embryos were further incubated for $72 \mathrm{~h}$ after administration. The anti-angiogenic response was assessed by counting. Five randomly chosen fields were evaluated for each specimen. The total vessels number of large vessels, small vessels and capillaries in the fields were counted, and the mean values \pm S.D. were calculated. The large, small vessels and capillaries meant the main blood vessels, vessels grown from main blood vessels and vessels grown from small vessels. The inhibitory effect on blood vessels could be observed by comparing the vascular change between the HMQ18-22 group and the negative control group.

Angiogenesis and tube formation of mouse colon tissue. An assay of mouse colon tissue co-cultured was used as the in vitro angiogenesis model. For preparation of fibrin matrices and matrigel, $3 \mathrm{mg} / \mathrm{ml}$ solution of fibrinogen containing $300 \mu \mathrm{g} / \mathrm{ml} \varepsilon$-aminocaproic acid (in DMEM) and matrigel (in DMEM) was incubated on ice for $10 \mathrm{~min}$. A sandwich structure was prepared in the 24-well plate (Costar, Corning, NY, USA). The colon tissues of mouse were cut into $0.5-1.0 \mathrm{~mm}^{3}$ tablets, placed into the sandwich structure, and covered with DMEM medium containing $20 \%$ bovine serum and HMQ18-22 (1.0, 4.0, $16.0 \mu \mathrm{mo} / / \mathrm{l})$ or vehicle alone. The sprouting vessels and tube formation were recorded and analyzed. The sprouting vessels and tube formation were assessed by counting. Five randomly chosen fields were evaluated. The total sprouting vessels and tube structures in the fields were counted, and the mean values \pm S.D. were calculated.

Tube formation assay. A 48-well plate coated with $0.2 \mathrm{ml}$ matrigel per well was allowed to solidify at $37^{\circ} \mathrm{C}$ for $1 \mathrm{~h}$. Each well was seeded with $1 \times 10^{4}$ HUVEC and cultured in DMEM containing $50 \mathrm{ng} / \mathrm{ml}$ VEGF at various concentrations $(1.0,2.0,4.0 \mu \mathrm{mol} / \mathrm{l})$ of HMQ18-22 or vehicle alone for $48 \mathrm{~h}$. The enclosed networks of tubes were photographed from five randomly chosen fields under a microscope.

Migration assay. A cell migration assay was performed using a transwell system, which allows cells to migrate throughout an 8- $\mu \mathrm{m}$ pore size polycarbonate membrane of millicell. ${ }^{33,34}$ HUVEC cells were plated $\left(10^{4}\right.$ cells/well) in medium containing HMQ18-22 at concentrations of $0.5,1.0,2.0,4.0,8.0 \mu \mathrm{mol} / \mathrm{l}$ in the upper chamber of a 12-well plate. The lower chamber was filled with $1.5 \mathrm{ml}$ medium containing $10 \% \mathrm{FBS}$. After $48 \mathrm{~h}$, cells remaining on the upper surface of the membrane were scraped and the cells on the lower surface of the membrane were fixed with cold methanol for $15 \mathrm{~min}$ and stained with $0.2 \%$ crystal violet. Cells that had migrated to the bottom of the membrane were visualized and counted using an inverted microscope. For each repetition, cells in five randomly selected fields were counted and averaged. Data were expressed as a ratio to the untreated group.

Lance assay for VEGFR2 kinase activity. VEGFR2 kinase was determined by lance assay. In all, $2 \mu \mathrm{l}$ kinase and $2 \mu \mathrm{l}$ substrate were added to the 384-well plate, and HMQ18-22 at various concentrations was then added to the assay plate. In all, $2 \mu \mathrm{l}$ ATP was added and the reaction was allowed to proceed at $37^{\circ} \mathrm{C}$ for $30 \mathrm{~min}$. The TK-antibody labeled with $\mathrm{Eu}^{3+}$-cryptate and streptavidin-XL665 was then added with EDTA to detect the phosphorylated product at room temperature for $1 \mathrm{~h}$. Then, the fluorescence of the resulting solution was measured at 665 and $615 \mathrm{~nm}$ using the plate reader of Perkin-Elmer victor 5 . The kinase activity was expressed by the ratio of $A 665 \times 10^{4} / A 615$.

AlphaScreen P-VEGFR assay. AlphaScreen assays for p-VEGFR proteins were carried out using SureFire assay kits (Perkin-Elmer). Lovo cells were seeded at a density of $1 \times 10^{4}$ cells per well in 96-well plates, HMQ18-22 at various concentrations $(2,4,8,16 \mu \mathrm{mol} / \mathrm{l})$ was added to the wells for $48 \mathrm{~h}$. The cells were treated with $100 \mathrm{ng} / \mathrm{ml}$ VEGF $15 \mathrm{~min}$ after serum starving overnight, lysed and agitated. Then, the reactions were carried out according to the assay kit instructions. The plates were read on an Enspire by Reader (Perkin-Elmer) using standard AlphaScreen settings. ${ }^{35,36}$

VEGF phospho antibody microarray analysis. The expression profile of VEGF phospho-related proteins was detected and analyzed using a human VEGF Phospho Antibody Array kit (PVE185, Fullmoon Biosystems, Sunnyvale, CA, USA). Protein microarray analysis was carried out using the protocol provided. Briefly, protein was extracted, lysate was purified and then the protein was labeled by biotinylation. The resulting biotin-labeled proteins were diluted 1:20 in coupling solution before being applied to the array for conjugation. To prepare the antibody 
microarray, it was blocked for 30 min, then dried and the array was incubated with the biotin-labeled cell lysates at $4{ }^{\circ} \mathrm{C}$. After the array slide was washed three times, the conjugation-labeled protein was detected by Cy3-Streptavidin. The analyzed results were expressed by the ratio of phosphorylation/unphosphorylation. ${ }^{37,38}$

Cell viability assay. Lovo cells $\left(1 \times 10^{4}\right)$ and HUVEC $\left(5 \times 10^{4}\right)$ were cultured in 96-well microtiter plates, and fresh medium with or without HMQ18-22, was added for $48 \mathrm{~h}$. Cell proliferation reagent WST-1 was added and incubated at $37^{\circ} \mathrm{C}$ and $5 \% \mathrm{CO}_{2}$ for $1 \mathrm{~h}$. Absorbance was then measured at $440 \mathrm{~nm}$ with a microplate reader (Bio-Rad, Hercules, CA, USA).

Transient transfection of siRNA. For in vitro knockdown experiments, a smart pool of double-stranded siRNA against VEGFR2, VEGFR1, Raf, PLC $\gamma$ and $\mathrm{PKC} \alpha$ as well as nonspecific siRNA was obtained from Shanghai GenePharma for transfection, siRNA was delivered at a final concentration of $50 \mathrm{nM}$ using Lipofectamine 2000 reagent (Invitrogen, Carlsbad, CA, USA) according to the manufacturer's instructions. ${ }^{39,40}$ The sense and antisense sequences were in Supplementary Table 1. We incubated the cells for $24 \mathrm{~h}$ to allow knockdown of VEGFR2, VEGFR1, Raf, $\mathrm{PLC} \gamma$ and $\mathrm{PKC} \alpha$. These cells were used for proliferation assays.

Western blot analysis. The tissues isolated from nude mice treated with or without HMQ18-22 and lovo cells treated with or without HMQ18-22 for 48 $\mathrm{h}$ were prepared by extracting proteins with RIPA lysis buffer containing protease inhibitor cocktail and phosphatase inhibitor cocktail on ice. Cell lysates were analyzed for western blot analysis with primary antibodies [VEGFR2(Tyr $\left.{ }^{1214}\right)$, VEGFR1 $\left(\mathrm{Tyr}^{1333}\right)$, Akt $\left(\mathrm{Tyr}^{326}\right), \mathrm{PKC} \alpha\left(\mathrm{Tyr}^{657}\right), \mathrm{PLC} \gamma-1\left(\mathrm{Tyr}^{771}\right)$ and Raf1 $\left.\left(\mathrm{Tyr}^{341}\right)\right]$, followed by enhanced chemiluminescence. ${ }^{41}$ The protein expression was analyzed using Quantity one, 1-D analysis software (Version 4.4, Bio-Rad).

Xenografted model in athymic mice. Tumors were induced in nude mice (male immune-deficient $\mathrm{BALB} / \mathrm{C}$ nude mice) by subcutaneous flank inoculation of $0.2 \mathrm{ml}$ lovo cell of $2 \times 10^{7} \mathrm{cell} / \mathrm{ml}$. Tumors were measured once every 3 days and tumor volumes $\left(V_{t}\right)\left[\left(I \times W^{2}\right) / 2\right]$ were calculated from caliper measurements. Mice were treated with HMQ18-22 (50.0 and $100.0 \mathrm{mg} / \mathrm{kg}$ in $0.5 \%$ CMC-Na; $n=8)$ or vehicle alone (0.5\% CMC-Na; $n=8)$ by intragastric administration. After 14 days, mice weight and tumor volume were recorded. The Institutional Animal Care and Use Committee approved all of the procedures performed in this study.

Statistical analysis. Statistical analyses of differences between the groups were performed with ANOVA by Student's $t$-tests. A $P$-value $<0.05$ was considered statistically significant.

\section{Conflict of Interest}

The authors declare no conflict of interest.

Acknowledgements. This work was supported by National Natural Science Foundation of China (Grant No. 81001447).

1. Carmeliet $P$, Jain RK. Angiogenesis in cancer and other diseases. Nature 2000; 407 249-257.

2. Folkman J. What is the evidence that tumors are angiogenesis dependent? $\mathrm{J}$ Natl Cancer Inst 1990; 82: 4-6.

3. Folkman J. Tumor angiogenesis: therapeutic implications. N Engl J Med 1971; 285: 1182-1186.

4. Folkman J. Antiangiogenesis in cancer therapy-endostatin and its mechanisms of action. Exp Cell Res 2006; 312: 594-607.

5. Jeanny B, Aragon-Ching A, William LD. Anti-angiogenesis approach to genitourinary cancer treatment. Update Cancer Ther 2009; 3: 182-188.

6. Wilhelm SM, Carter C, Tang L. BAY 43-9006 exhibits broad spectrum oral antitumor activity and targets the RAF/MEK/ERK pathway and receptor tyrosine kinases involved in tumor progression and angiogenesis. Cancer Res 2004; 64: 7099-7109.

7. Strimpakos A, Saif MW, Syrigos K. Pancreatic cancer: from molecular pathogenesis to targeted therapy. Cancer Metastasis Rev 2008; 27: 495-522.

8. Chow LQ, Eckhardt SG. Sunitinib: from rational design to clinical efficacy. J Clin Oncol 2007; 25: 884-896.

9. Zhang J, Shan YY, Pan XY, He LC. Recent advances in antiangiogenic agents with VEGFR as target. Mini Rev Med Chem 2011; 1: 920-946.
10. Matsumoto $\mathrm{T}$, Mugishima $\mathrm{H}$. Signal transduction via vascular endothelial growth factor (VEGF) receptors and their roles in atherogenesis. J Atheroscler Thromb 2006; 13: $130-135$.

11. Zhong $\mathrm{H}$, Bowen JP. Molecular design and clinical development of VEGFR kinase inhibitors. Curr Top Med Chem 2007; 7: 1379-1393.

12. Ferrara N, Gerber HP, LeCouter J. The biology of VEGF and its receptors. Nat Med 2003 9: 669-676.

13. Soltau J, Drevs J. Mode of action and clinical impact of VEGF signaling inhibitors. Expert Rev Anticancer Ther 2009; 9: 649-662.

14. Veeravagu A, Hsu AR, Cai W, Hou LC, Tse VC, Chen X. Vascular endothelial growth factor and vascular endothelial growth factor receptor inhibitors as anti-angiogenic agents in cancer therapy. Recent Pat Anticancer Drug Discov 2007; 2: 59-71.

15. Munoz-Chapuli R, Quesada AR, Angel MM. Angiogenesis and signal transduction in endothelial cells. Cell Mol Life Sci 2004; 61: 2224-2243.

16. Jiang BH, Liu LZ. AKT signaling in regulating angiogenesis. Curr Cancer Drug Targets 2008; 8: 19-26.

17. Berra E, Milanini J, Richard DE, Le Gall M, Viñals F, Gothié E et al. Signaling angiogenesis via p42/p44 MAP kinase and hypoxia. Biochem Pharmacol 2000; 60: 1171-1178.

18. Takahashi T, Shibuya M. The $230 \mathrm{kDa}$ mature form of KDR/Flk-1 (VEGF receptor-2) activates the PLC-gamma pathway and partially induces mitotic signals in NIH3T3 fibroblasts. Oncogene 1997; 4: 2079-2089.

19. Li YP, He LC. Establishment of the model of vascular endothelial cell membrane chromatography and its preliminary application. Chin Sci Bull 2007; 52: 922-928.

20. Zhang J, Zhang YM, Pan XY, Wang SC, He LC. Synthesis and cytotoxic evaluation of novel symmetrical taspine derivatives as anticancer agents. Med Chem 2011; 7: 286-294.

21. Zhang J, Zhang YM, Shan YY, Li N, Ma W, He LC. Synthesis and preliminary biological evaluation of novel taspine derivatives as anticancer agents. Eur J Med Chem 2010; 45 2798-2805.

22. Huh JE, Baek YH, Lee MH, Choi DY, Park DS, Lee JD. Bee venom inhibits tumor angiogenesis and metastasis by inhibiting tyrosine phosphorylation of VEGFR2 in LLCtumor-bearing mice. Cancer Lett 2010; 292: 98-110.

23. Zhang YM, He LC, Meng L, Luo WJ, Xu XM. Suppression of tumor-induced angiogenesis by taspine isolated from Radix et Rhizoma Leonticis and its mechanism of action in vitro. Cancer Lett 2008; 262: 103-113.

24. Wells A, Grandis JR, Phospholipase C. $\gamma 1$ in tumor progression. Clin Exp Metastasis 2003; 20: 285-290.

25. Piccolo E, Innominato PF, Mariggio MA, Maffucci T, lacobelli S, Falasca M. The mechanism involved in the regulation of phospholipase Cgamma1 activity in cell migration. Oncogene 2002; 21: 6520-6529.

26. Kim MJ, Si F, Kim SJ, Hong SB, Hwang JI, Lee HJ et al. The SH2-SH2-SH3 domain of phospholipase C-gamma1 directly binds to translational elongation factor-1alpha. Mol Cells 1999; 9: 631-637.

27. Rhee SG, Choi KD. Regulation of inositol phospholipid-specific phospholipase $C$ isozymes J Biol Chem 1992; 267: 12393-12396.

28. Wheatley-Price P, Shepherd FA. Epidermal growth factor receptor inhibitors in the treatment of lung cancer: reality and hopes. Curr Opin Oncol 2008; 20: 162-175.

29. Zinda MJ, Johnson MA, Paul JD, Horn C, Konicek BW, Lu ZH et al. AKT-1,-2, and-3 are expressed in both normal and tumor tissues of the lung, breast, prostate, and colon. Clin Cancer Res 2001; 7: 2475-2479.

30. Zhan YX, Sun M, Chen YN, Zhang YM. Determination of Taspine Using HPLC-MS and its Effect on EGFR in A431 and HEK293/EGFR Cells in Vitro. Chromatographia 2011; 74 383-389.

31. Kirchenr LM, Schmidt SP, Gruber BS. Quantitation of angiogenesis in the chick chorioallantoic membrane model using fractal analysis. Microvasc Res 1996; 51: 2-14.

32. Siamblis D, Karnabatidis D, Hatjikondi O, Kalogeropoulou C, Kardamakis D, Dimopoulos J. A novel radiological approach for the experimental study of angiogenesis: angiography of the chick embryo and its chorioallantoic membrane. Eur J Radiol 1996; 21: 220-224.

33. Adams LS, Phung S, Yee N, Seeram NP, Li L, Chen S. Blueberry phytochemicals inhibit growth and metastatic potential of MDA-MB-231 breast cancer cells through modulation of the phosphatidylinositol 3-kinase pathway. Cancer Res 2010; 70: 3594-3605.

34. Yang Y, Marcello M, Endris V, Saffrich R, Fischer R, Trendelenburg MF et al. MEGAP impedes cell migration via regulating actin and microtubule dynamics and focal complex formation. Exp Cell Res 2006; 312: 2379-2393.

35. Kylie MW, David AJ. Intramolecular masking of nuclear localization signals: analysis of importin binding using a novel AlphaScreen-based method. Anal Biochem 2006; 348: 49-56.

36. Pedro L, Padrós J, Beaudet L, Schubert HD, Gillardon F, Dahan S. Development of a highthroughput AlphaScreen assay measuring full-length LRRK2(G2019S) kinase activity using moesin protein substrate. Anal Biochem 2010; 404: 45-51.

37. Zhong D, Liu X, Khuri FR, Sun SY, Vertino PM, Zhou W. LKB1 is necessary for Aktmediated phosphorylation of proapoptotic proteins. Cancer Res 2008; 68: 7270-7277.

38. Ratna BR, Raychoudhuri A, Steele R, Nerurkar P. Bitter Melon (Momordica charantia) extract inhibits breast cancer cell proliferation by modulating cell cycle regulatory genes and promotes. Apoptosis 2010; 70: 1925-1931.

39. Akaogi K, Nakajima Y, Ito I, Kawasaki S, Oie SH, Murayama A et al. KLF4 suppresses estrogen-dependent breast cancer growth by inhibiting the transcriptional activity of Era. Oncogene 2009; 28: 2894-2902. 
40. Kortylewski M, Swiderski P, Herrmann A, Wang L, Kowolik C, Kujawski M et al. In vivo delivery of siRNA to immune cells by conjugation to a TLR9 agonist enhances antitumor immune responses. Nat Biotechnol 2009; 27: 925-932.

41. Kim HJ, Oh GS, Lee JH, Lyu AR, Ji HM, Lee SH et al. Cisplatin ototoxicity involves cytokines and STAT6 signaling network. Cell Res 2011; 21: 944-956.
Cell Death and Disease is an open-access journal POMERIEHTS RESERVED published by Nature Publishing Group. This work is
licensed under the Creative Commons Attribution-NonCommercial-No Derivative Works 3.0 Unported License. To view a copy of this license, visit http://creativecommons.org/licenses/by-nc-nd/3.0/

Supplementary Information accompanies the paper on Cell Death and Disease website (http://www.nature.com/cddis) 